\title{
Viscoelastic, Spectroscopic, and Microscopic Characterization of Novel Bio-Based Plasticized Poly(vinyl chloride) Compound
}

\author{
Mei Chan Sin, ${ }^{1}$ Irene Kit Ping Tan, ${ }^{1,2}$ Mohd Suffian Mohd Annuar, ${ }^{1}$ and Seng Neon Gan ${ }^{3}$ \\ ${ }^{1}$ Institute of Biological Sciences, Faculty of Science, University of Malaya, 50603 Kuala Lumpur, Malaysia \\ ${ }^{2}$ Centre for Research in Biotechnology for Agriculture (CEBAR), University of Malaya, 50603 Kuala Lumpur, Malaysia \\ ${ }^{3}$ Department of Chemistry, Faculty of Science, University of Malaya, 50603 Kuala Lumpur, Malaysia
}

Correspondence should be addressed to Mei Chan Sin; meichansin112@gmail.com

Received 17 February 2014; Accepted 5 April 2014; Published 5 May 2014

Academic Editor: Jan-Chan Huang

Copyright (C) 2014 Mei Chan Sin et al. This is an open access article distributed under the Creative Commons Attribution License, which permits unrestricted use, distribution, and reproduction in any medium, provided the original work is properly cited.

\begin{abstract}
Plasticized poly(vinyl chloride) (PVC) is one of the most widely consumed commodity plastics. Nevertheless, the commonly used plasticizers, particularly phthalates, are found to be detrimental to the environment and human health. This study aimed to investigate the ability of an alternative greener material, medium-chain-length polyhydroxyalkanoates (mcl-PHA), a kind of biopolyester and its thermally degraded oligoesters, to act as a compatible bioplasticizer for PVC. In this study, mcl-PHA were synthesized by Pseudomonas putida PGA1 in shake flask fermentation using saponified palm kernel oil (SPKO) and subsequently moderately thermodegraded to low molecular weight oligoesters (degPHA). SEM, ATR-FTIR, ${ }^{1} \mathrm{H}-\mathrm{NMR}$, and DMA were conducted to study the film morphology, microstructure, miscibility, and viscoelastic properties of the PVC-PHA and PVC/degPHA binary blends. Increased height and sharpness of $\tan \delta_{\max }$ peak for all binary blends reveal an increase in chain mobility in the PVC matrix and high miscibility within the system. The PVC-PHA miscibility is possibly due to the presence of specific interactions between chlorines of $\mathrm{PVC}$ with the $\mathrm{C}=\mathrm{O}$ group of $\mathrm{PHA}$ as evidenced by spectroscopic analyses. Dynamic viscoelastic measurements also showed that mcl-PHA and their oligoesters could reduce the $T_{g}$ of PVC, imparting elasticity to the PVC compounds and decreasing the stiffness of PVC.
\end{abstract}

\section{Introduction}

Poly(vinyl chloride) (PVC) constitutes one of the largest globally consumed commodity plastics, approximately 16 million tonnes per annum [1]. PVC compounds in the plasticized form are widely used in the industry for various flexible applications such as packaging, toys, and medical and household products. Conventional petrochemical-based plasticizers for PVC, particularly phthalates, for example, diethylhexyl phthalates (DEHP) and diisononyl phthalates (DINP), are the predominant type of PVC plasticizer and accounted for almost $86 \%$ of the world consumption of plasticizers in 2008 [2, 3].

Nevertheless several issues regarding the use of phthalates were raised recently, concerning the effects of phthalates on the environment, human hormones, and reproductive system as well as their exposures to children via breast milk, toys, and baby care products. Based on a study in Norway, the bronchial obstruction in children was directly related to the amount of plasticizer-releasing materials present in the indoor environment [4]. According to Bornehag et al. (2005), plasticizers that are present in the dust are the main elements causing allergy, asthma and inducing puberty among the children since they spent most of the time indoors [5]. Another study showed that the phthalates actually mimicked female hormones and could serve as the endocrine disruptors in human body, resulting in feminization of boys [6]. Recently in the 2011 Taiwan Food Scandal, DEHP and DINP were reported as the carcinogenic plasticizer agents, implicated in human infertility problem and developmental problems in children. Research also showed that phthalates were responsible for cancer proliferation in mice and rats [7]. These phthalate-based plasticizers are found to be harmful to human beings through direct contact with skin and tissues. The risk of them leaching out from PVC compounds during end-used applications to the environment or human body 
is significant. Therefore intense researches have been carried out to seek alternative green plasticizer materials, which impart low toxicity, total or partial biodegradability and are economically and technically viable to substitute the conventional petrochemical-based plasticizers.

Medium-chain-length polyhydroxyalkanoates (mclPHA) are bacterial polyesters comprised of six to fourteen carbon-chain-length monomers [8-10], which have biodegradable [11], biocompatible [12], and nontoxic [13] properties. In addition, mcl-PHA can be synthesized from natural renewable resources such as plant oil [14], fatty acids [15], and agricultural wastes [16]. Thus, mcl-PHA fulfill all the desirable traits of an alternative eco-friendly plasticizer material. These bacterially produced polymers have sufficiently high molecular weight in the range of 50,000 to 300,000 Dalton [17]. As mcl-PHA also exhibit polar properties, they have great potential to act as compatible plasticizer for PVC. In addition, possible entanglement between the PHA with PVC may not allow for easy migration of the plasticizers out of the blended compounds. Low molecular weight oligoesters can be produced from mcl-PHA by thermal degradation process. These oligomeric hydroxyalkanoic acids possess favorable end groups, and such fragments could be used as PVC plasticizers as well. This is different from the conventional petrochemical-based plasticizers which are small molecules that intercalate into PVC and thus may have limited residence time in the PVC compound. In the event of accidental or natural migration from the blended compounds, the PHA plasticizers would not be hazardous to human health and the environment due to their nontoxic, biodegradable, and biocompatible properties.

In this work, saponified palm kernel oil (SPKO)-derived mcl-PHA and their low molecular weight oligoesters were mixed with PVC at the compositions of 2.5 and 5 parts per hundred parts (phr) of PVC through solution blending. The PVC/PHA binary blends were solvent-casted and characterized to study the polymer film morphology, microstructure, PVC-PHA interactions, miscibility between the two polymers, and viscoelastic properties of the PVC/PHA polymer blends.

\section{Experimental Sections}

2.1. Materials. Poly(vinyl chloride) (PVC) with molecular weight approximately $100,000 \mathrm{~g} \mathrm{~mol}^{-1}$ (BDH laboratory reagent) was used throughout the experiments. Mcl-PHA were produced in a two-stage culture system which consisted of cell-growth phase and PHA-accumulation phase. In the first phase, the Pseudomonas putida PGA1 were grown in nutrient broth $\left(8.0 \mathrm{~g} \mathrm{~L}^{-1}\right)$, a nutritionally rich medium, to produce high concentration of cells. After 20 hours of incubation, the cells were harvested by centrifugation at $8000 \mathrm{rpm}$ for 30 minutes at $4^{\circ} \mathrm{C}$, then washed with $0.85 \%$ saline, and transferred to the modified nitrogen-limiting M9 medium [18], containing $0.5 \%(\mathrm{w} / \mathrm{v})$ saponified palm kernel oil (SPKO) [19] as the sole carbon source, to induce PHA biosynthesis by the cells. The bacteria were further cultivated in PHA production medium for 72 hours at $200 \mathrm{rpm}$ and $30^{\circ} \mathrm{C}$. The bacterial cells were then aseptically harvested by centrifugation. The cells were washed twice with sterile $0.85 \%$ saline and dried at $70^{\circ} \mathrm{C}$ in a hot air oven to constant weight. The dried cells were washed with polar solvent to remove residual carbon substrates and metabolic wastes from the biomass by suspending them in $95 \%$ analytical grade ethanol and shaking for 30 minutes at $22 \pm 1^{\circ} \mathrm{C}$ and $160 \mathrm{rpm}$ in the orbital shaker incubator. Oily residues and other polar lipids attached to the cells would dissolve in the alcohol which was decanted off. The cells were then dried in oven at $70^{\circ} \mathrm{C}$ to constant weight. Intracellular mcl-PHA were extracted by suspending the dried cells in analytical grade chloroform and refluxed for 6 hours at $70^{\circ} \mathrm{C}$. The PHAchloroform solution was filtered through Whatman number 1 filter paper to remove the cellular debris, and the filtrate was concentrated by rotary evaporation. The biopolymers were purified by drop-wise addition of the extract into rapidly stirred methanol chilled with ice bath. Further purification was carried out by redissolving the PHA in a small amount of chloroform and reprecipitating it in excess methanol. It was then dried in a vacuum oven at $37^{\circ} \mathrm{C}, 0.6 \mathrm{~atm}$, for 48 hours. Low molecular weight PHA oligoesters were produced through mild thermal degradation of the polymer. The mclPHA samples were thermally degraded at temperatures of $170^{\circ} \mathrm{C}$. At such temperature, the heat-treated PHA (degPHA) is mainly composed of a mixture of oligomeric hydroxy acid fragments without terminal unsaturated fragments. The thermal degradation process was performed using similar procedure as described earlier $[15,18,20]$.

2.2. Gel Permeation Chromatography (GPC) Analysis of PHA and $\operatorname{deg} P H A$. The number average molecular weight $\left(M_{n}\right)$, weight average molecular weight $\left(M_{w}\right)$, and polydispersity index $(P D I)$ of PHA and degPHA used in the blending were determined by gel permeation chromatography (GPC) analysis. GPC was performed using a Waters 600-GPC (USA) instrument equipped with Waters Styragel HR columns $(7.8 \mathrm{~mm}$ internal diameter $\times 300 \mathrm{~mm})$ connected in series (HR1, HR2, HR5E, and HR5E) and a Waters 2414 refractive index detector. Approximately $100.0 \mu \mathrm{L}$ of $2.0 \mathrm{mg} \mathrm{mL}^{-1}$ polymer sample was eluted by THF at a flow rate of $1 \mathrm{~mL} \mathrm{~min}^{-1}$ at $40^{\circ} \mathrm{C}$. The instrument was calibrated using monodisperse polystyrene standards.

\subsection{Gas Chromatography (GC) Analysis of PHA and degPHA.} Analysis of PHA and degPHA monomeric compositions was performed using a GC 2014 Shimadzu (Japan) equipped with a SGE forte GC capillary column BP20 $(30 \mathrm{~m} \times$ $0.25 \mathrm{~mm}$ internal diameter $\times 0.25 \mu \mathrm{m}$ ) (Australia) and a flame ionization detector (FID). In the GC analysis, $1.0 \mu \mathrm{L}$ of sample was injected by split injection with a split ratio of $10: 1$ using a SGE $10.0 \mu \mathrm{L}$ syringe. Nitrogen was used as the carrier gas at a flow rate of $3 \mathrm{~mL} \mathrm{~min}^{-1}$. The column oven temperature was programmed from $120^{\circ} \mathrm{C}$ for $2 \mathrm{~min}$ at the start, ramped up at a rate of $20^{\circ} \mathrm{C} \mathrm{min}^{-1}$ to $230^{\circ} \mathrm{C}$, and held at this temperature for $10 \mathrm{~min}$. The temperatures of injector and detector were set at $225^{\circ} \mathrm{C}$ and $230^{\circ} \mathrm{C}$, 
respectively. 3-Hydroxyalkanoic acid methyl ester standards, 3-hydroxybutyric acid $\left(3 \mathrm{HB} ; \mathrm{C}_{4}\right)$, 3-hydroxyhexanoic acid $\left(3 \mathrm{HH}_{x} ; \mathrm{C}_{6}\right)$, 3-hydroxyoctanoic acid $\left(3 \mathrm{HO} ; \mathrm{C}_{8}\right), 3-$ hydroxydecanoic acid $\left(3 \mathrm{HD} ; \mathrm{C}_{10}\right)$, 3-hydroxydodecanoic acid $\left(3 \mathrm{HDD} ; \mathrm{C}_{12}\right)$, 3-hydroxytetradecanoic acid $\left(3 \mathrm{HTD} ; \mathrm{C}_{14}\right)$, and 3-hydroxyhexadecanoic acid $\left(3 \mathrm{HH}_{x} \mathrm{D} ; \mathrm{C}_{16}\right)$ methyl esters (Larodan), were used to determine the respective retention times for monomer identification.

2.4. Blending of PHA and degPHA with PVC. A $0.625 \%$ w/v of PHA solution (20.0 mL chloroform containing $0.125 \mathrm{~g}$ PHA) and $1.25 \% \mathrm{w} / \mathrm{v}$ of PHA solution $(20.0 \mathrm{~mL}$ chloroform containing $0.25 \mathrm{~g}$ mcl-PHA) were prepared. These solutions were then added to the $5 \% \mathrm{w} / \mathrm{v}$ PVC solution $(100.0 \mathrm{~mL}$ chloroform containing $5.0 \mathrm{~g}$ of PVC) at two ratios, yielding $2.5 \mathrm{phr}$ (parts per hundred PVC resin) and $5 \mathrm{phr}$ (parts per hundred PVC resin) of PVC/PHA binary blends, respectively. The binary blends were designated as, for example, $\mathrm{PSP}_{2.5}$ and $\mathrm{PdeSP}_{2.5}$, representing blends of 2.5-part polymeric PHA and oligomeric degPHA with 97.5-part PVC, respectively, and $\mathrm{PSP}_{5}$ and $\mathrm{PdeSP}_{5}$ representing blends of 5-part polymeric PHA and oligomeric degPHA with 95-part PVC, respectively.

The lightly plasticized PVC films were prepared by mixing mcl-PHA at compositions of 2.5 and 5 parts per hundred (phr) parts of PVC resin by solution blending, using chloroform (analytical grade, Merck) as the common solvent. The solution blends were poured into glass Petri dishes and dried in vacuum oven at $70^{\circ} \mathrm{C}$ for one week to remove residual solvent. The $\mathrm{PVC} / \mathrm{chloroform}$ solution was first mixed at $500 \mathrm{rpm}$ and refluxed at $55^{\circ} \mathrm{C}$ in a flat round bottom flask connected to Liebig condenser with a reduction adaptor for 30 minutes. After the specified reaction time, the $\mathrm{PHA} /$ chloroform solution was added to the PVC solution and the mixture was allowed to mix thoroughly at $500 \mathrm{rpm}$ and $55^{\circ} \mathrm{C}$ for one hour. The reactor was placed in a thermostated water bath and the level of the water was kept at least $2 \mathrm{~cm}$ above the level of the solution in the reaction flask for homogeneous temperature equilibrium. Upon completion of blending, the PVC/PHA was solvent-casted in a glass Petri dish and was stirred to slowly evaporate off the solvent in the fume hood at room temperature. The casted films were further dried under vacuum at 60 to $70^{\circ} \mathrm{C}$ for two days followed by drying in hot air oven at 70 to $72^{\circ} \mathrm{C}$ for one week to allow for complete removal of the traces of residual solvent.

2.5. Characterizations of PVC-PHA Binary Blends. The casted $\mathrm{PVC} / \mathrm{PHA}$ films were studied by various analytical techniques such as scanning electron microscopy (SEM), attenuated total reflectance-Fourier transform infrared spectroscopy (ATRFTIR), proton nuclear magnetic resonance spectroscopy $\left({ }^{1} \mathrm{H}\right.$ NMR), and dynamic mechanical analysis (DMA), for the polymer film morphology, PVC-PHA interactions, miscibility between the two polymers, and viscoelastic properties.

2.5.1. Scanning Electron Microscopy (SEM). The PVC/PHA sample films were examined by scanning electron microscopy (SEM) to study the microstructure and surface morphology of the thin films. SEM microscopy was performed using a SEM Zeiss Auriga (Germany) under magnifications of 500x. Uncoated samples were used in this SEM study, using low operating voltage around $1 \mathrm{kV}$ and $\mathrm{LaB}_{6}$, Field Emission as electron source. Samples were mounted onto the specimen holder using conducting carbon-impregnated tape. At normal operating voltages $(10$ to $30 \mathrm{kV})$, the contrast differences between phases with different compositions are inherently lower in resolution in the backscattered (BS) image than the secondary image [21]. By working at low operating voltages, subtle variations in the chemical compositions of blend components are sufficient to produce contrast in the secondary images and therefore high-quality images are possible to be obtained.

\subsubsection{Attenuated Total Reflectance-Fourier Transform Infrared} Spectroscopy (ATR-FTIR). The structural and functional groups present in the PVC, PHA, and PVC/PHA samples were analyzed by Perkin-Elmer FTIR-ATR spectrometer (USA). The IR spectra of the thin films prepared were scanned at a wavelength of 4000 to $450 \mathrm{~cm}^{-1}$, with a resolution of $4 \mathrm{~cm}^{-1}$, and recorded after 4 scans.

2.5.3. Proton Nuclear Magnetic Resonance Spectroscopy $\left({ }^{1} \mathrm{H}-\right.$ NMR). ${ }^{1} \mathrm{H}-\mathrm{NMR}$ analysis of PVC, PHA, and PVC/PHA samples was carried out on a JEOL JNM-LA 400 FT-NMR spectrometer (Japan) operating at $400 \mathrm{MHz}$. About $20.0 \mathrm{mg}$ of the sample was dissolved in $1 \mathrm{~mL}$ of deuterated chloroform. The integration value of $\alpha$-methine proton (-CHCl-) of PVC was chosen as the reference and was assigned the value of 1.00.

2.5.4. Dynamic Mechanical Analysis (DMA). Miscibility between two polymers is usually characterized by using dynamic mechanical analysis (DMA). DMA is also an alternative method to study the viscoelastic properties of a polymer blend, for example, storage modulus $\left(E^{\prime}\right)$, loss modulus $\left(E^{\prime \prime}\right)$, and loss angle tangent $(\tan \delta)$ [22]. Generally, for an immiscible blend, the loss modulus curves show the presence of two damping peaks corresponding to the $T_{g} \mathrm{~s}$ of individual components [23]. For a highly miscible blend, the curve shows only a single peak, whereas broadening of the transition occurs in the case of partially miscible systems [24].

In this study, viscoelastic properties of PVC/PHA polymer blends were characterized by TA DMA Q800 dynamic mechanical analyzer using a tension film clamp. Before being subjected to the mechanical testing, sample films were prepared using a hot press (Carver Instrument, Model C, $\mathrm{S} / \mathrm{N}$ 40000-715). Specimens were heated, pressed to a specific temperature at $4.5 \mathrm{psi}$ applied load, and held for $2 \mathrm{~min}$, followed by cooling to ambient temperature. Strips of thin films with $30.0 \mathrm{~mm}$ fixed length were then mounted to the TA DMA Instrument and the measurements were made under the temperature scan mode ranging from -40 to $120^{\circ} \mathrm{C}$, under a heating rate of $5^{\circ} \mathrm{C} \mathrm{min}^{-1}$ and at a frequency of $1 \mathrm{~Hz}$. Liquid nitrogen was used in the Cryospeed, the cooling accessory, to achieve subambient temperature in this testing.

Mechanical properties of polymer show profound changes in the region of the glass transitions. For example, the elastic modulus may decrease by a factor of over 
1000 times as the temperature is raised through the glass transition region. For this reason, $T_{g}$ can be considered the most important material characteristic of a polymer as far as mechanical properties are concerned. Besides that, $T_{g}$ has important theoretical implications for the understanding of the macromolecular mobility in the polymer. $T_{g}$ can be determined from the onset of the storage modulus $\left(E^{\prime}\right)$ drop, the onset or peak of loss modulus $\left(E^{\prime \prime}\right)$, and the onset or peak of the $\tan \delta$ curve [25]. In our analysis, the $T_{g}$ values were determined from the maximum peak of loss modulus curves. All temperatures were recorded in degrees Celsius.

\subsection{Study of Elastic Modulus of PVC/PHA Blends. Elastic} modulus is the mathematical description of a polymer's tendency to be deformed elastically when a force is applied to it. It is a measure of the stiffness of a component. A stiff component, with a high elastic modulus, will show much smaller changes in dimensions. In general, engineering applications view stiffness as a function of both the elastic modulus and the geometry of a component. Elastic modulus (E) of PVC/PHA and PHV/degPHA samples was determined by adapting the elastic modulus equation from the model equation in the TA DMA Q800 Equation Guideline, with the relationship of the stiffness, elastic modulus, and sample's geometry for the sample analyzed on a film tension clamp as shown below:

$$
K=\frac{(A \times E)}{L}
$$

where $K$ is stiffness $\left(\mathrm{N} \mathrm{m}^{-1}\right), E$ is elastic modulus $\left(\mathrm{G} \mathrm{N} \mathrm{m}^{-2}\right)$, $A$ is sample cross-sectional area $\left(\mathrm{cm}^{2}\right)$, and $L$ is sample length $(\mathrm{cm})$. As the sample has a very small area as compared to its length, no end effects correction is needed; therefore, the modulus equation is derived as follows:

$$
E=K_{s} \times \frac{L}{A}
$$

where $E$ is elastic modulus $\left(\mathrm{GN} \mathrm{m}^{-2}\right), A$ is sample crosssectional area $\left(\mathrm{cm}^{2}\right), L$ is sample length $(\mathrm{cm})$, and $K_{s}$ is measured stiffness $\left(\mathrm{N} \mathrm{m}^{-1}\right)$.

\section{Results and Discussion}

3.1. Molecular Weight and Monomer Composition of PHA $A_{S P K O}$ and $\operatorname{deg} P \mathrm{HA}_{\mathrm{SPKO}}$. The average molecular weight and molecular weight distribution of both $\mathrm{PHA}_{\mathrm{SPKO}}$ and degPHA $\mathrm{SPKO}_{\mathrm{S}}$ were determined by GPC analysis and the results were summarized in Table 1. As shown in the table, the number average molecular weight $\left(M_{n}\right)$ and weight average molecular weight $\left(M_{w}\right)$ of $\mathrm{PHA}_{\mathrm{SPKO}}$ decreased when the polymers were heat-treated at $170^{\circ} \mathrm{C}$. Heating $\mathrm{PHA}_{\mathrm{SPKO}}$ at $170^{\circ} \mathrm{C}$ resulted in the reduction of molecular weight, producing a mixture of low molecular weight hydroxyl alkanoic acids. Besides that, an increase in polydispersity index $(P D I)$ in degPHA was observed, and this indicated that these polymers had broader molecular weight distribution, as various lower-molecularweight species were generated at high temperature of partial thermal degradation.
Table 1 also shows the relative monomer compositions

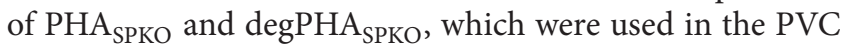
blending. The oligomeric PHA contained higher amount of shorter side chain monomers $\left(\mathrm{C}_{6}\right.$ and $\left.\mathrm{C}_{8}\right)$, compared to the polymeric PHA. For example, the amount of shorter side chain monomers for $\operatorname{deg} \mathrm{PHA}_{\mathrm{SPKO}}$ was $52.1 \mathrm{wt} \%$, which was higher than those shorter side chain monomers present in $\mathrm{PHA}_{\text {SPKO }}(50.8 \mathrm{wt} \%)$.

3.2. SEM of PVC, PHA, PVC/PHA, and PVC/degPHA Films. SEM is used to examine the surface variations of polymer blends and provide qualitative comparisons for blends morphology [21]. In order to understand how the surface morphology of the PVC film changes with the introduction of plasticizers, the SEM micrographs of the pure PVC, PHA, $\mathrm{PHA} / \mathrm{PVC}$, and PHA/degPVC films were taken.

As shown in Figure 1(a), cavities were present in the individual PVC film. The pores were distributed throughout the surface with the pore size in the range of 1 to $20 \mu \mathrm{m}$. These observations were similar to the findings reported by Stephan et al. (2000) [26]. Figure 1(b) showed the surface morphology of SPKO-derived PHA ( PHA $\left._{\mathrm{SPKO}}\right)$ film. $\mathrm{PHA}_{\mathrm{SPKO}}$ physically and morphologically existed as softer and amorphous material and thus appeared as a smooth film without any cavity. After mixing the PVC with both PHA and degPHA, the cavities were not as clearly observed as in pure PVC film, but the PHA and PVC resin molecules were observed to be engaged in a continuous solvation-desolvation phase while the PVC resin macromolecules were joining in a continuous aggregation-disaggregation phase (Figures 1(c)$1(f))$. As could be seen in the figures, the PHA could be penetrated to some of the porous structures of PVC and interfused with the PVC polymer segments.

3.3. ATR-FTIR Analysis of PVC/PHA System. ATR-FTIR spectroscopy is often used in the analysis of polymer blend. In this study, ATR-FTIR spectroscopy was used to investigate whether specific interaction between the PHA and PVC had taken place, which could be observed from the shift of certain peaks in the spectrum. The characteristic bands of PVC can be classified into three regions: (i) the $\mathrm{C}-\mathrm{Cl}$ stretching region in the range from 600 to $700 \mathrm{~cm}^{-1}$; (ii) the $\mathrm{C}-\mathrm{C}$ stretching in the range from 900 to $1200 \mathrm{~cm}^{-1}$, and (iii) from 1250 to $2970 \mathrm{~cm}^{-1}$, attributed to numerous C-H modes in PVC [27]. On the other hand, the mcl-PHA polyesters had characteristic strong absorbance bands at around $1726 \mathrm{~cm}^{-1}$, which were attributed to the $\mathrm{C}=\mathrm{O}$ stretching. Therefore, it is convenient to differentiate the PHA from PVC by the carbonyl band.

Figure 2 shows the ATR-FTIR absorption spectra of PVC, PHA, PVC/PHA, and PVC/degPHA blends. All the blends showed the characteristic peaks of both $\mathrm{PHA}$ and $\mathrm{PVC}$ components, that is, the $\mathrm{C}=\mathrm{O}$ stretching band at around 1737 to $1740 \mathrm{~cm}^{-1}$ and $\mathrm{C}-\mathrm{Cl}$ stretching around 607 to $610 \mathrm{~cm}^{-1}$, indicating that both polar functional groups of mcl-PHA and PVC were present in the polymer blends. As shown in Figure 2(a), the $\mathrm{C}=\mathrm{O}$ stretching frequency for $\mathrm{PHA}_{\mathrm{SPKO}}$ was observed at $1726 \mathrm{~cm}^{-1}$. After mixing the PVC with 2.5 and 5 phr of PHA $_{\mathrm{SPKO}}$, the peak maximum position was 


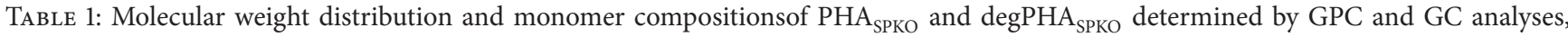
respectively.

\begin{tabular}{lccccccccc}
\hline \multirow{2}{*}{ Sample } & \multicolumn{3}{c}{ Molecular weight distribution } & \multicolumn{4}{c}{ Monomer composition (wt\%) } \\
& ${ }^{1} M_{n}$ & ${ }^{2} M_{w}$ & ${ }^{3} \mathrm{PDI}$ & $\mathrm{C}_{6}$ & $\mathrm{C}_{8}$ & $\mathrm{C}_{10}$ & $\mathrm{C}_{12}$ & $\mathrm{C}_{14}$ & $\mathrm{C}_{14: 1}$ \\
\hline PHA $_{\mathrm{SPKO}}$ & 32700 & 60000 & 1.8 & 4.5 & 46.3 & 32.6 & 13.4 & 1.6 \\
$\operatorname{degPHA}_{\mathrm{SPKO}}$ & 18200 & 42000 & 2.3 & 4.9 & 47.2 & 32.4 & 1.6 \\
\hline
\end{tabular}

${ }^{1} M_{n}$ : number average molecular weight; ${ }^{2} M_{w}$ : weight average molecular weight; ${ }^{3}$ PDI: polydispersity index; $\mathrm{C}_{6}: 3$-hydroxyhexanoic acid; $\mathrm{C}_{8}$ : 3hydroxyoctanoic acid; $\mathrm{C}_{10}$ : 3-hydroxydecanoic acid; $\mathrm{C}_{12}: 3$-hydroxydodecanoic acid; $\mathrm{C}_{14}: 3$-hydroxytetradecanoic acid; $\mathrm{C}_{14: 1}: 3$-hydroxytetradecenoic acid.

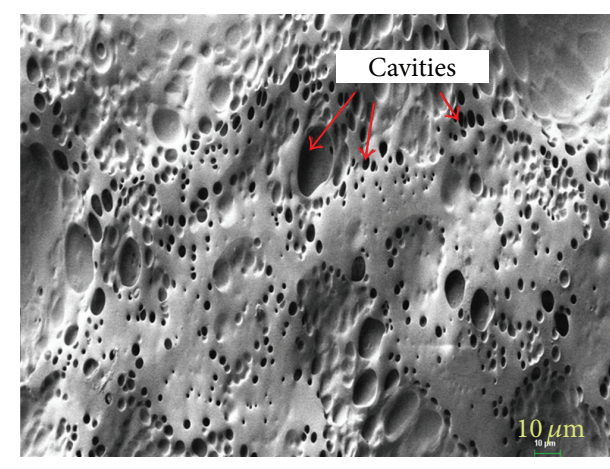

(a)

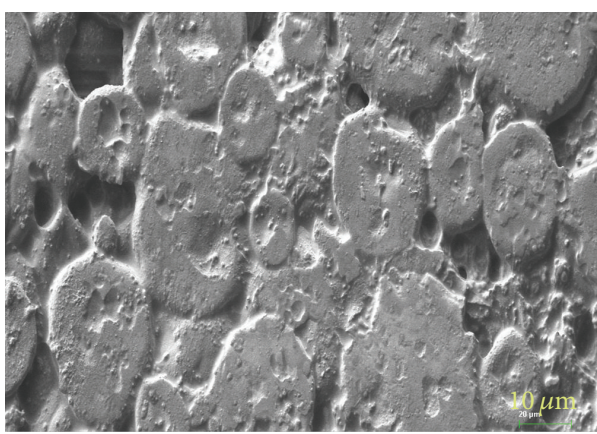

(c)

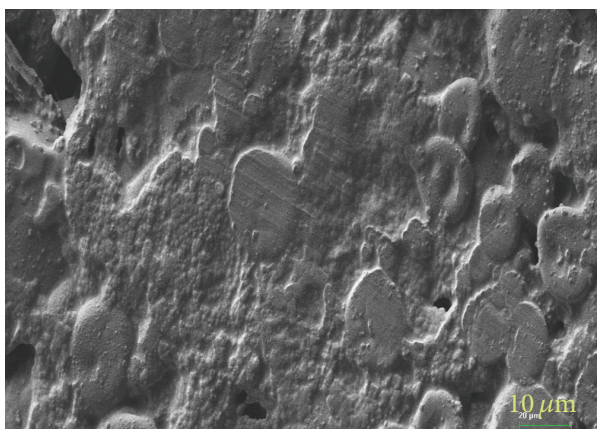

(e)

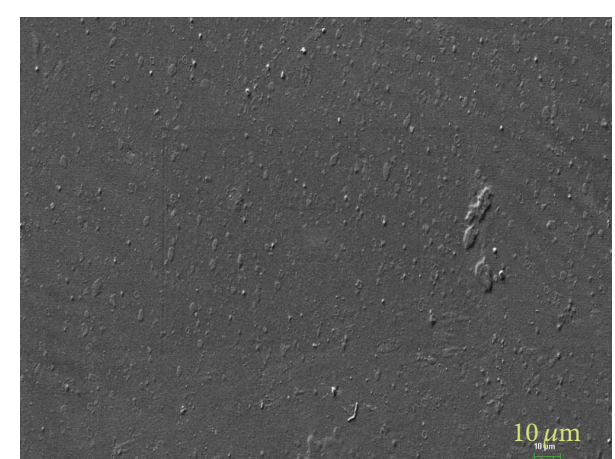

(b)

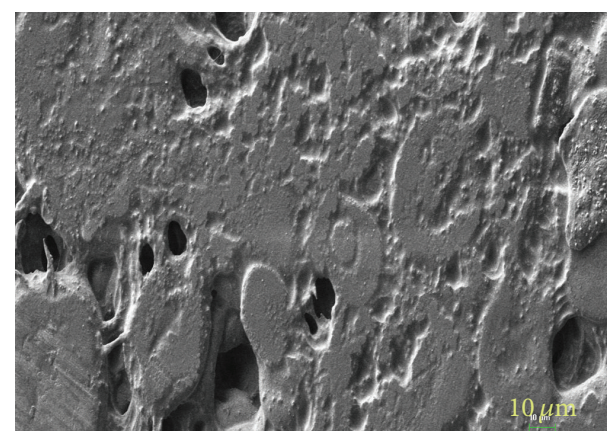

(d)

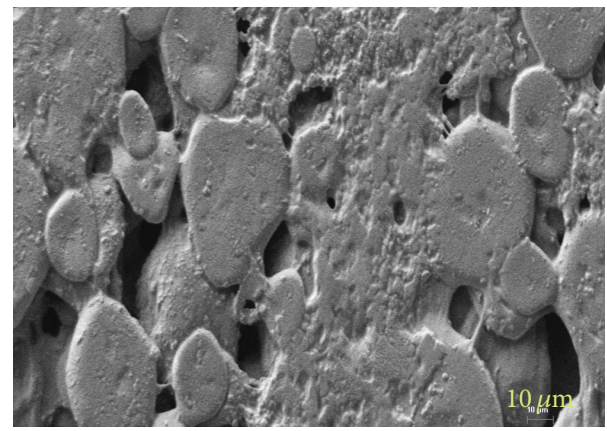

(f)

FIGURE 1: SEM micrograph showing surface morphology of (a) PVC, (b) $\mathrm{PHA}_{\mathrm{SPKO}}$, (c) $\mathrm{PSP}_{2.5}$, (d) $\mathrm{PSP}_{5}$, (e) $\mathrm{PdegSP}_{2.5}$, and (f) PdeSP films $_{5}$ (500x magnification).

shifted to higher frequency, that is, $1737 \mathrm{~cm}^{-1}$ for $\mathrm{PSP}_{5}$ and $1740 \mathrm{~cm}^{-1}$ for $\mathrm{PSP}_{2.5}$. Similarly, the ester carbonyl stretching

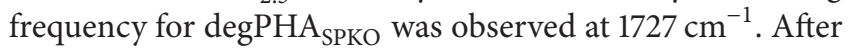
mixing the PVC with 2.5 and 5 phr of $\operatorname{degPHA} \mathrm{PPKO}_{\mathrm{S}}$, the peak maximum position was shifted to $1738 \mathrm{~cm}^{-1}$ for PdeSP $\mathrm{P}_{5}$ and $1739 \mathrm{~cm}^{-1}$ for $\mathrm{PdeSP}_{2.5}$. On the other hand, the shift of the
$\mathrm{C}-\mathrm{Cl}$ stretching frequency from $616 \mathrm{~cm}^{-1}$ (PVC) to lower frequencies was also observed in the blends, with PSP at 607 to $608 \mathrm{~cm}^{-1}$ and PdeSP at 609 to $610 \mathrm{~cm}^{-1}$. From the observations for the shift of both ester carbonyl and $\mathrm{C}-\mathrm{Cl}$ stretching in all polymer blends, it is believed that the $\mathrm{C}=\mathrm{O}$ group in PHA could be responsible for the miscibility with 


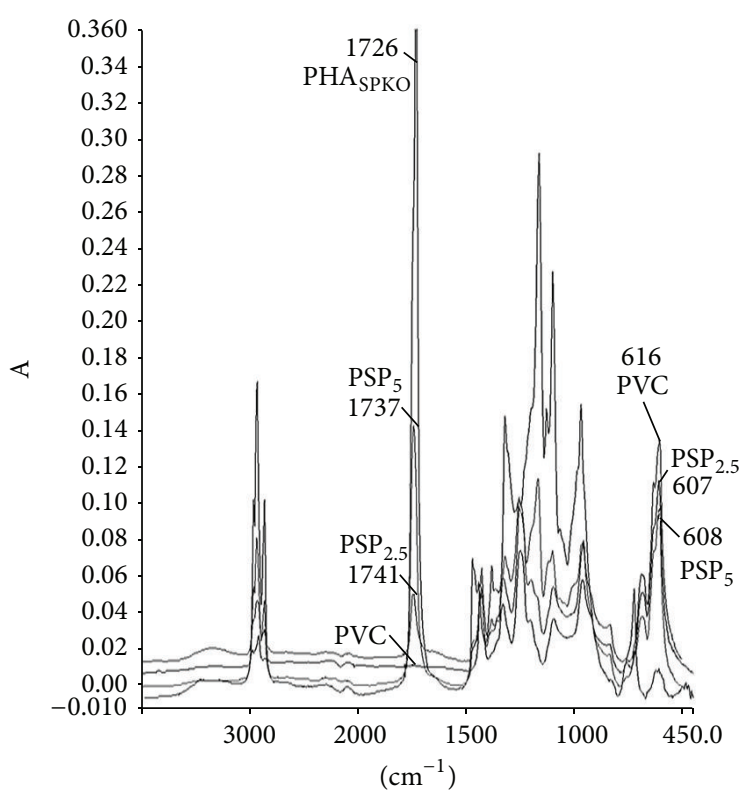

(a)

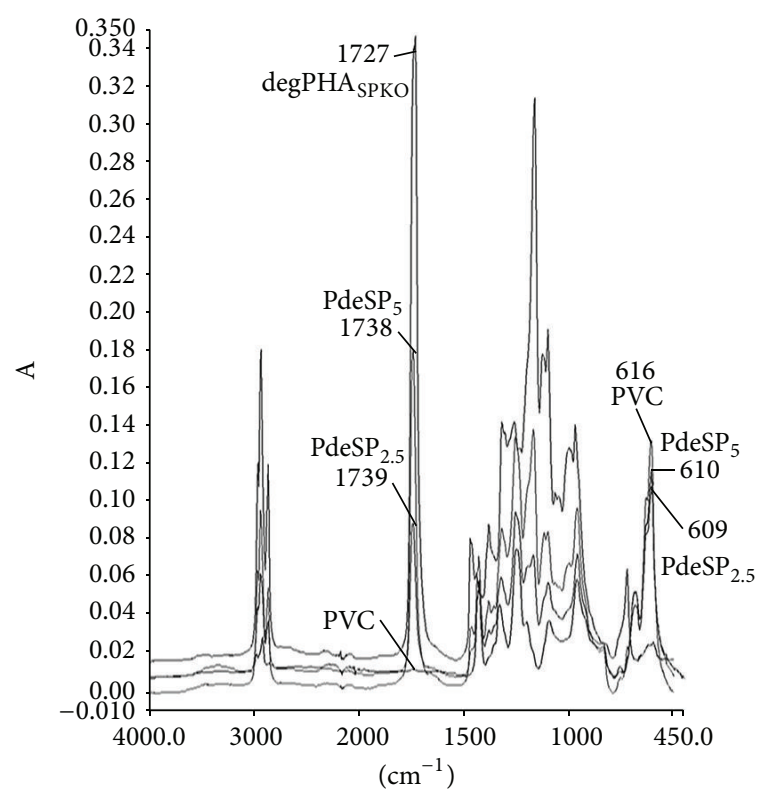

(b)

FIgURE 2: ATR-FTIR absorption spectra of (a) PVC, PHA SPKO $_{\text {, and PSP and (b) PVC, degPHA }}$ SPKO, and PdeSP.

the PVC. Therefore, it is hypothesized that specific polar interactions between the PHA and PVC had taken place.

The relative intensity ratio between absorbance value for $\mathrm{C}=\mathrm{O}$ stretching in PHA and nonreactive $\mathrm{CH}$ bending in PVC $\left(A_{1739} / A_{1426}\right)$ for $\mathrm{PSP}_{2.5}, \mathrm{PdeSP}_{2.5}, \mathrm{PSP}_{5}$, and PdeSP was $0.47,0.39,0.76$, and 0.63 , respectively. PVC blended with $\mathrm{PHA}_{\text {SPKO }}\left(M_{w} 60000 \mathrm{~g} / \mathrm{mol}\right)$ had higher relative ratio of $A_{1739} / A_{1426}$ than with those blended with $\operatorname{degPHA}{ }_{\text {SPKO }}\left(M_{w}\right.$ $42000 \mathrm{~g} / \mathrm{mol}$ ) since PHA $_{\text {SPко }}$ has higher molecular weight and longer polyester chain which subsequently has more ester $\mathrm{C}=\mathrm{O}$ carbonyl group. Thus the polymeric PHA may have increased level of interaction with the PVC. On the other hand, PVC blended with $5 \mathrm{phr}$ PHA had higher relative ratio of $A_{1739} / A_{1426}$ than with $2.5 \mathrm{phr}$ PHA. As higher amount of PHA is present in the polymer mixture, higher amount of polar groups in the polymer is available for possible interaction with PVC. It should be noted that polar groups in a plasticizer are essential for good compatibility as it is the case of like dissolving like. When plasticizer molecules are introduced into the polymer mass, polymer chains are separated by the plasticizer molecules, which are able to line up their dipoles with the polymer dipoles. Polymer chains separated in this way are more easily moved relative to the ones that are bonded very closely. In addition, high molecular weight of a plasticizer reduces its ability to shield polymer dipoles, with this subsequently reducing the mobility among the polymer chain [28].

3.4. ${ }^{1} H$-NMR Analysis of PVC/PHA System. Nuclear magnetic resonance (NMR) spectroscopy is one of the techniques which could provide information on a molecular dimension scale for the polymer-polymer interaction. Figure 3 showed the proton NMR spectra for PVC, PHA, PVC/PHA, and $\mathrm{PVC} / \operatorname{deg} \mathrm{PHA}$ blend, respectively.

In Figure 3(a), the peaks around 4.3 to $4.6 \mathrm{ppm}$ were assigned to the $\alpha$-methine proton $(-\mathrm{CHCl}-)$ which attached to the electropositive carbon atom, and peaks around 1.9 to $2.3 \mathrm{ppm}$ were assigned to the $\beta$-methylene proton $\left(-\mathrm{CH}_{2}-\right)$ in PVC. The relative intensity ratio of ${ }^{\alpha} \mathrm{H}(\alpha$-methine proton) to ${ }^{\beta} \mathrm{H}$ ( $\beta$-methylene proton) was $1: 2$, in agreement with the structure of the repeating unit. The peak at $1.5 \mathrm{ppm}$ was due to the moisture in the $\mathrm{D}$-chloroform. This could be due to the relatively low solubility of PVC in the chloroform and therefore small amount of water in the solvent could be detected in the spectrum. Figure 3(b) showed the ${ }^{1} \mathrm{H}-\mathrm{NMR}$ spectrum of PHA. The peak $a$ at $0.8 \mathrm{ppm}$ and peak $b$ at $1.2 \mathrm{ppm}$ were assigned to the methyl $\left(-\mathrm{CH}_{3}\right)$ and methylene $\left(-\left(\mathrm{CH}_{2}\right)_{n}{ }^{-}\right)$group in the PHA side chain, respectively. Peak $c$ at around $1.5 \mathrm{ppm}$ was assigned to the methylene $\left(-\mathrm{CH}_{2}-\right)$ group attached to the carbon adjacent to the oxygen atom. These three peaks $a, b$, and $c$ are the characteristic peaks of PHA, which could be used to validate the presence of polyester in the polymer blends. The peak $d$ at around $2.5 \mathrm{ppm}$ represented the methylene group at the $\alpha$-position of the ester.

As could be seen from Figures 3(c)-3(f), the spectra of PVC/PHA and PVC/degPHA blends showed almost identical peaks as PVC, with three additional peaks being detected: $0.8 \mathrm{ppm}, 1.2 \mathrm{ppm}$, and $1.5 \mathrm{ppm}$, which are assignable to $\mathrm{CH}_{3},-\left(\mathrm{CH}_{2}\right)_{n}-$, and $-\mathrm{CH}_{2}-$ groups in PHA, respectively. The integration of these peaks appeared to be much smaller in the PVC/PHA blends, revealing that only small amount of PHA was present in the blends. A new small peak at around $2.5 \mathrm{ppm}$, as indicated by the arrows, appeared in the 


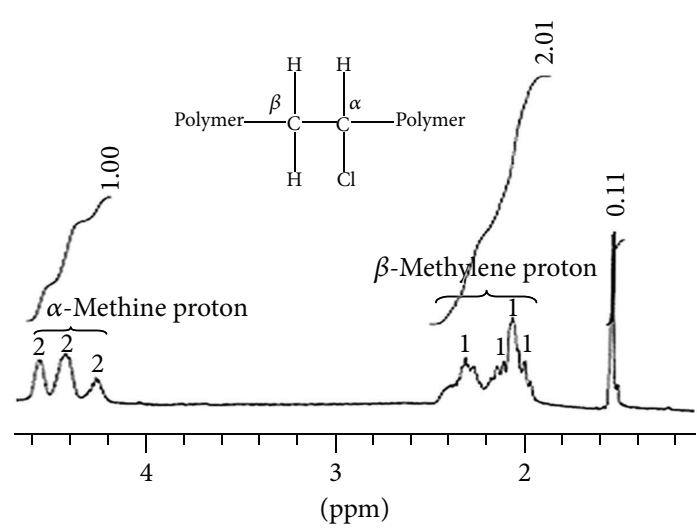

(a) PVC

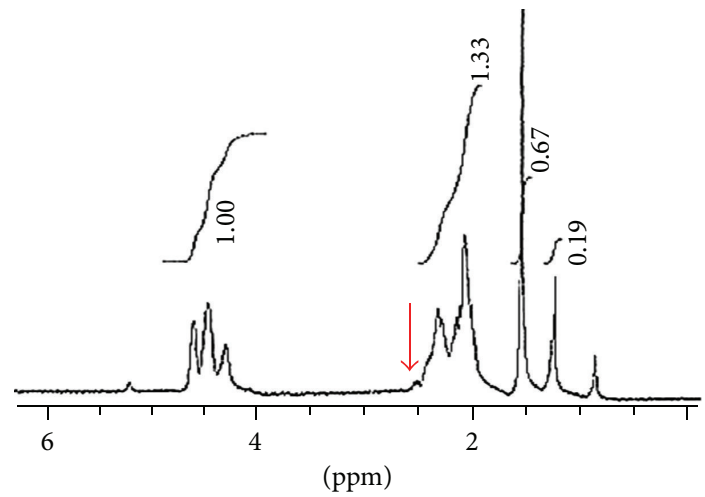

(c) $\mathrm{PSP}_{2.5}$

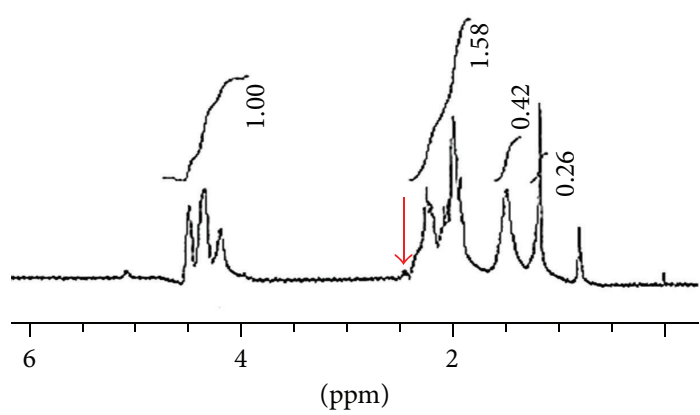

(e) PdegSP $_{2.5}$

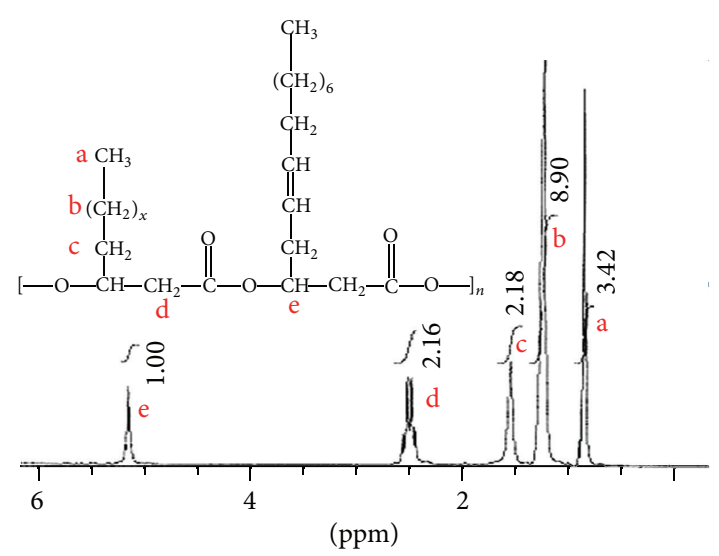

(b) $\mathrm{PHA}_{\mathrm{SPKO}}$

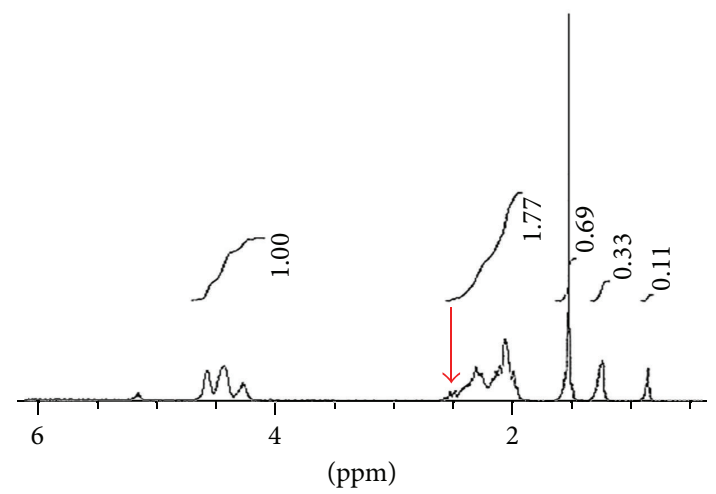

(d) $\mathrm{PSP}_{5}$

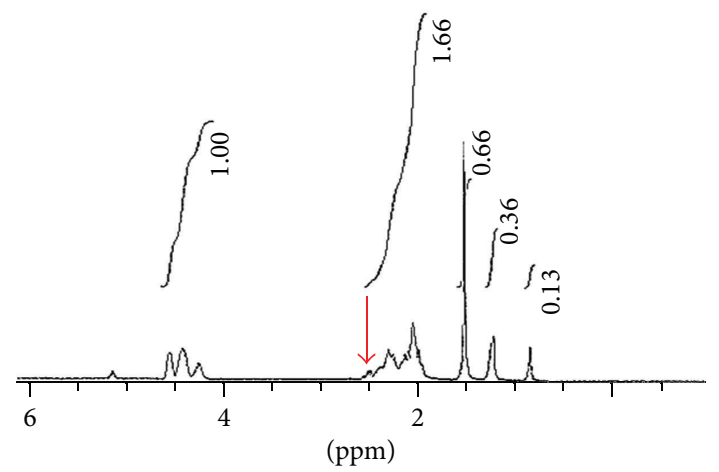

(f) $\mathrm{PdeSP}_{5}$

Figure 3: ${ }^{1} \mathrm{H}-\mathrm{NMR}$ spectra of (a) PVC, (b) $\mathrm{PHA}_{\mathrm{SPKO}}$, (c) PS , (d) $\mathrm{PSP}_{5}$, (e) PdegSP 2.5 , and (f) PdeSP 5 binary blends.

PVC/PHA and PVC/degPHA blend. This peak was ascribed to the $\alpha$-hydrogen adjacent to the ester group in PHA, which was partially overlapped with the peak broadening of beta$\mathrm{H}$ in PVC. From these observations, it was proposed that specific intermolecular interactions could be present within the polymer mixtures and the two polymers may intermingle with each other on a molecular level.

3.5. Dynamic Mechanical Analysis of PVC/PHA System. Mechanical compatibility with property conciliation between the components is assured for a miscible and compatible polymer mixture. Dynamic mechanical analysis (DMA) is a method commonly employed to provide direct quantitative measurement of the modulus explicating phase transition behavior as a function of temperature $[29,30]$. The difference between homogeneous and heterogeneous blends is easily detected in the mechanical loss and modulus-temperature data. A miscible polymer blend usually shows a single and unique transition in the modulus-temperature curve [31].

A miscible system is formed when there are specific polymer-polymer interactions in a mixture of two polymers. These miscible blends are expected to show a single $T_{g}$ 


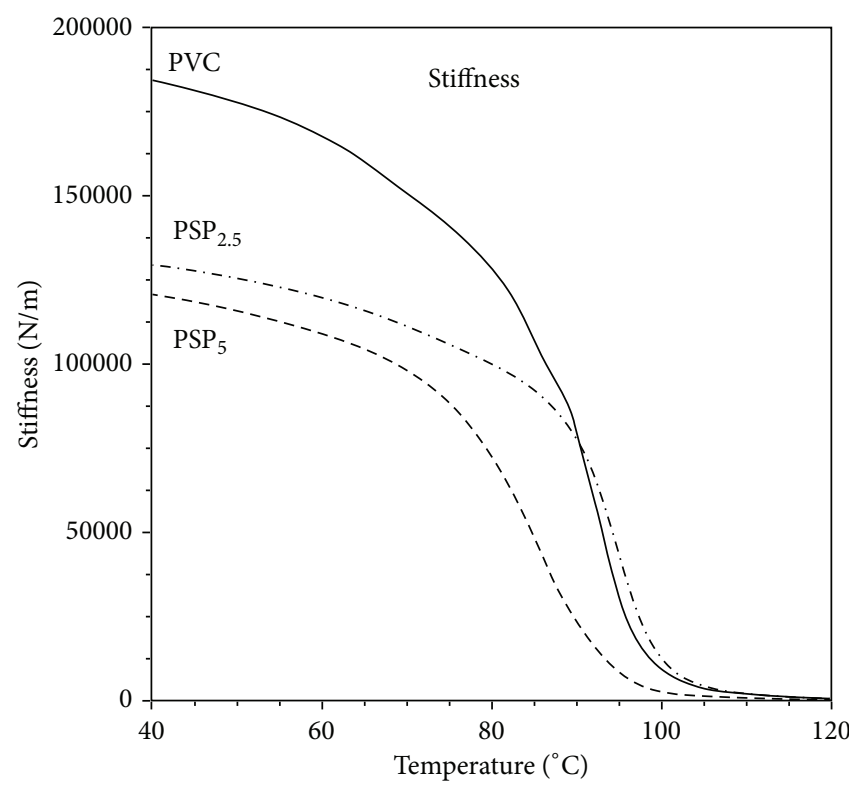

(a)

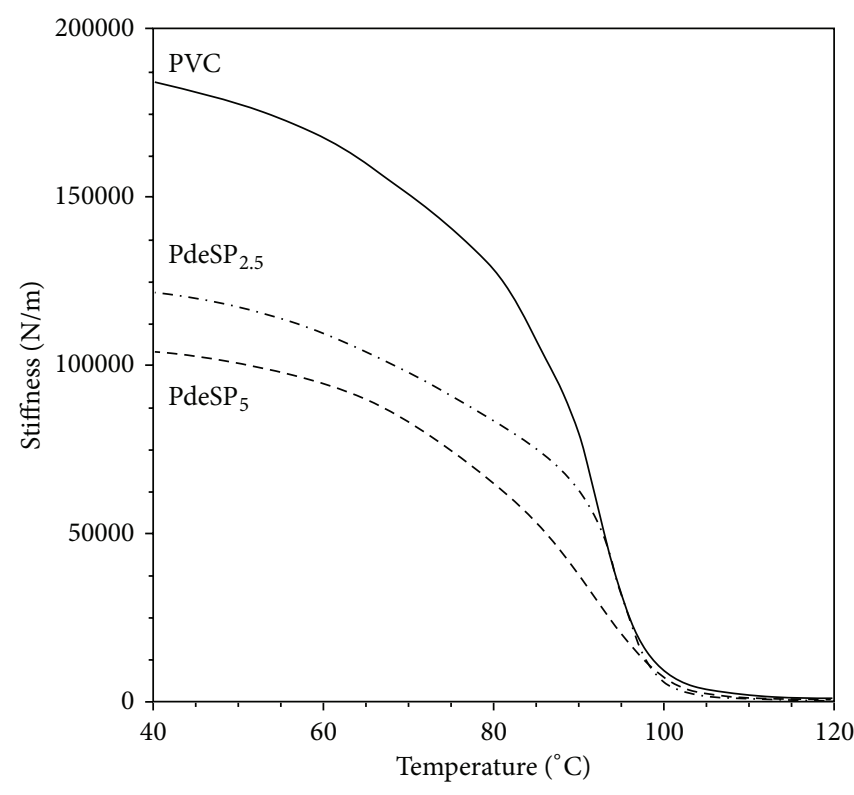

(b)

Figure 4: Temperature variation of film's stiffness for (a) PVC, $\mathrm{PSP}_{2.5}$, and $\mathrm{PSP}_{5}$ and (b) PVC, $\mathrm{PdeSP}_{2.5}$, and PdeSP ${ }_{5}$.

value and a single modulus transition zone, which varies regularly with the blend composition [32]. In this study, $T_{g}$ was determined from the maximum peak of loss modulus $\left(E^{\prime \prime}\right)$ curve. Both PVC and $\mathrm{PHA}_{\mathrm{SPKO}}$ have $T_{g}$ of $91.9^{\circ} \mathrm{C}$ and $-36.8^{\circ} \mathrm{C}$, respectively. On the other hand, dynamic mechanical measurements showed a single $T_{g}$ for all PVC/PHA $\left(T_{g}\right.$ : $83.4^{\circ} \mathrm{C}$ for $\mathrm{PSP}_{2.5}$ and $T_{g}: 82.7^{\circ} \mathrm{C}$ for $\mathrm{PSP}_{5}$ ) and PVC/degPHA $\left(T_{g}: 80.9^{\circ} \mathrm{C}\right.$ for $\mathrm{PdeSP}_{2.5}$ and $T_{g}: 79.7^{\circ} \mathrm{C}$ for $\mathrm{PdeSP}_{5}$ ) binary blends, revealing that the PHA were highly miscible with PVC. Overall the $T_{g}$ of all plasticized PVC were lower than the PVC, with $T_{g}$ of $\mathrm{PVC} / \mathrm{PHA}_{5}$ lower than $\mathrm{PVC} \mathrm{PHA}_{2.5}$ and $T_{g}$ of PVC/degPHA lower than PVC/PHA. A higher content of PHA in PVC/PHA led to a lower $T_{g}$ value. This means that the plasticization of PVC was enhanced by higher amounts of PHA. This could be due to more PHA embedding themselves between the PVC chains, thus spacing the latter further apart to increase the polymer chain mobility. Polymer blends composed of PVC and the oligoesters as plasticizer showed lower $T_{g}$ than the blends composed of polymeric polyesters. As low molecular weight plasticizers possessed more end groups, this would accordingly increase the mobility among the PVC polymer chains; thus softer plasticized films with better plasticizing effect would be formed.

Apart from that, a ratio of loss modulus $\left(E^{\prime \prime}\right)$ to storage modulus $\left(E^{\prime}\right)$ is known as the loss angle tangent $(\tan \delta)$ which represents the main relaxation associated with the glass-rubber transition. It is the dissipation factor which is defined as the loss modulus over the storage modulus. This value (dimensionless) can be attributed to the change from rigidity to flexibility [33]. The tan delta peak maximum $\left(\tan \delta_{\max }\right)$ of PVC was about 0.74. All PVC/PHA showed higher and sharper $\tan \delta_{\max }$ peak compared to PVC (data not shown), indicating the high miscibility of the system. All binary blends have higher values of $\tan \delta_{\max }$ than the PVC showing some level of dynamic homogeneity in the blend. In other words, the blends appear to be miscible and have a narrow range of relaxation times. This may be due to the close molecular proximity of the like chains. Overall the values of $\tan \delta_{\max }$ for $\mathrm{PVC} / \mathrm{PHA}_{5}$ are higher than $\mathrm{PVC} \mathrm{PHA}_{2.5}$ and PVC/degPHA higher than PVC/PHA.

The increase in the $\tan \delta_{\max }$ in PVC/PHA was possibly due to the reduction in the crystalline volume of the PVC system in the presence of PHA plasticizer. According to Madera-Santana et al. (2009), a reduction of sharpness and height of the $\tan \delta_{\max }$ peak is due to the restriction of the chain mobility in the polymer [34]. Therefore, increasing the PHA content of the blend increases the chain mobility in the PVC matrix and led to a sharper and height increment of $\tan \delta_{\max }$ during dynamic mechanical deformation. The values of $\tan \delta_{\max }$ of all binary blends approach 1.00 indicating that backbone chains in the polymer blends exhibit gradual slippage and result in a springy and rubbery nature of plasticized PVC compound.

It is known that the extent of decrease in stiffness and changes in the softness of the plasticized PVC depend on both the level of plasticization and the nature of the plasticizer [35]. As discussed earlier, introduction of the plasticizer into the polymer system greatly increased the mobility among the polymer chain, and this subsequently augmented the softening of the polymer. Figure 4 revealed the temperature variation of film's stiffness for all the plasticized PVC.

As shown in Figure 4, the stiffness of PVC/PHA was decreased when the proportion of PHA was increased. According to Wypych (2004), when larger quantities of plasticizers were added into the PVC, more amorphous areas of the PVC were swollen [36]. This would lead to increased ease of movement of the macromolecules, thus making the 
plasticized PVC more flexible. This could be seen from the decreased stiffness of the binary blends when the amount of PHA was increased in the blend. On the other hand, by comparing the film's stiffness of the PVC/PHA with $\mathrm{PVC} / \mathrm{degPHA}$ blends at $40^{\circ} \mathrm{C}$, it could be seen that addition of low molecular weight PHA could provide greater flexibility to the PVC compared to high molecular weight PHA, by introducing greater internal lubrication effect. The effectiveness in the lubrication effect could be attributed to the widespread specific interactions between the shorter chain fragments of low molecular weight PHA with PVC, promoted by the increased hydroxyl and carboxyl end groups.

\subsection{Comparison of Elastic Modulus of PVC and PVC/PHA} Binary Blends. Elastic modulus $(E)$ is the mathematical description of a polymer's tendency to be deformed elastically when a force is applied to it. It is a measure of the stiffness of a component. A stiff component, with a high elastic modulus, will show much smaller changes in dimensions. In general, engineering applications view stiffness as a function of both the elastic modulus and the geometry of a component. For rigid PVC, typical elastic modulus lies between 2.4 and $4.1 \mathrm{GPa}$. In this study, the calculated elastic modulus for the pure PVC was around 3.92 GPa. All PVC/PHA and PVC/degPHA blends showed a considerable lower elastic modulus than pure PVC. Overall, the effectiveness of reducing the elastic modulus of the polymer was found to be better in PVC/PHA 5 (E: $1.72 \mathrm{GPa}$ for $\mathrm{PSP}_{5}$ and $E: 1.49 \mathrm{GPa}$ for PdeSP 2.5 ) as compared to PVC/PHA 2.5 (E: $3.26 \mathrm{GPa}$ for $\mathrm{PSP}_{2.5}$ and $E$ : $1.94 \mathrm{GPa}$ for PdeSP 2.5 ); better in PVC/degPHA compared to PVC/PHA.

Decreased elastic modulus was observed in the polymer blends with higher amounts of PHA, and PHA in the form of oligoesters. When higher amount of PHA was added to the PVC, more amorphous areas of the PVC particles would be swollen and this would lead to increased ease of movement of the PVC macromolecules, whereas oligomeric PHA would augment the degree of chain movement and segmental flexibility to the PVC chains in a greater extent and would therefore increase the softening properties of the blends.

\section{Conclusions}

SEM micrographs of PVC/PHA and PVC/degPHA films showed that introduction of low amount of PHA in the binary blends results in penetration of PHA polymers into some of the porous structures of PVC and subsequently interfused with PVC polymer segments. Spectroscopic analyses confirmed the presence of both polar functional groups of PHA and PVC in the binary blends. It is postulated that the PVCPHA miscibility was due to the specific interactions between the polar ester groups of PHA with the $\mathrm{CH}-\mathrm{Cl}$ group of $\mathrm{PVC}$. DMA measurements showed a single $T_{g}$ for all PVC/PHA and $\mathrm{PVC} / \operatorname{deg} \mathrm{PHA}$, indicating that the PHA were miscible with PVC. Decreased $T_{g}$, stiffness, and elastic modulus were observed in the polymer blends with higher amounts of PHA, and PHA in the form of oligoesters. When larger quantities of PHA plasticizers were added to the PVC, more amorphous areas of the PVC particles would be swollen and this would lead to increased ease of movement of the PVC macromolecules. On the other hand, low molecular weight PHA would increase the degree of chain movement and segmental flexibility to the PVC chains to a greater extent and would therefore impart plasticization effect to PVC more effectively, compared to high molecular weight PHA. In summary, mclPHA and the oligoesters were shown to be a compatible plasticizer for PVC as they have reasonable apparent affinity towards the PVC resin due to the presence of some levels of intermolecular attraction between the polymers and they could impart flexibility to the PVC compound.

\section{Conflict of Interests}

The authors declare that there is no conflict of interests regarding the publication of this paper.

\section{Acknowledgment}

The authors wish to acknowledge the support of the University of Malaya, through research Grants 39-02-03-9057, PS 155/2009A, and PS 295/2010B.

\section{References}

[1] PVC Information Council, PVC Factsheet No. 2, European Council of Vinyl Manufacturers, 1995.

[2] A. Marcilla, S. García, and J. C. García-Quesada, "Study of the migration of PVC plasticizers," Journal of Analytical and Applied Pyrolysis, vol. 71, no. 2, pp. 457-463, 2004.

[3] S. Bizzari, M. Blagoev, and A. Kishi, (SRI Consulting, Menlo Park, Calif, USA), 2009.

[4] Plastermart, "An overview of plasticizers and their effects on human health and environment," Technical articles and reports on plastic industry, 2008.

[5] C.-G. Bornehag, B. Lundgren, C. J. Weschler, T. Sigsgaard, L. Hagerhed-Engman, and J. Sundell, "Phthalates in indoor dust and their association with building characteristics," Environmental Health Perspectives, vol. 113, no. 10, pp. 1399-1404, 2005.

[6] Third national report on human exposure to environmental chemicals, Department of Health \& Human Services, Atlanta (CDC, U. S.) , 2005.

[7] National Toxicology Program. No. NTP Tech. Rep. Ser. TR no. 217, 1982.

[8] A. Timm and A. Steinbuchel, "Formation of polyesters consisting of medium-chain-length 3-hydroxyalkanoic acids from gluconate by Pseudomonas aeruginosa and other fluorescent pseudomonads," Applied and Environmental Microbiology, vol. 56, p. 3360, 1990.

[9] A. Ballistreri, M. Giuffrida, S. P. P. Guglielmino, S. Carnazza, A. Ferreri, and G. Impallomeni, "Biosynthesis and structural characterization of medium-chain-length poly(3hydroxyalkanoates) produced by Pseudomonas aeruginosa from fatty acids," International Journal of Biological Macromolecules, vol. 29, no. 2, pp. 107-114, 2001.

[10] M. C. Sin, S. N. Gan, M. S. M. Annuar, and I. K. P. Tan, "Chain cleavage mechanism of palm kernel oil derived medium-chainlength poly(3-hydroxyalkanoates) during high temperature 
decomposition," Polymer Degradation and Stability, vol. 96, no. 9, pp. 1705-1710, 2011.

[11] S. P. Lim, S. N. Gan, and I. K. P. Tan, "Degradation of medium-chain-length polyhydroxyalkanoates in tropical forest and mangrove soils," Applied Biochemistry and Biotechnology, vol. 126, no. 1, pp. 23-33, 2005.

[12] G.-Q. Chen and Q. Wu, "The application of polyhydroxyalkanoates as tissue engineering materials," Biomaterials, vol. 26, no. 33, pp. 6565-6578, 2005.

[13] S. F. Williams, D. P. Martin, D. M. Horowitz, and O. P. Peoples, "PHA applications: addressing the price performance issue: I. Tissue engineering," International Journal of Biological Macromolecules, vol. 25, no. 1- 3, pp. 111-121, 1999.

[14] M. C. Sin, I. K. P. Tan, M. S. M. Annuar, and S. N. Gan, "Characterization of oligomeric hydroxyalkanoic acids from thermal decomposition of palm kernel oil-based biopolyester," International Journal of Polymer Analysis and Characterization, vol. 16, no. 5, pp. 337-347, 2011.

[15] M. C. Sin, S. N. Gan, M. S. M. Annuar, and I. K. P. Tan, "Thermodegradation of medium-chain-length poly(3hydroxyalkanoates) produced by Pseudomonas putida from oleic acid," Polymer Degradation and Stability, vol. 95, no. 12, pp. 2334-2342, 2010.

[16] J. Yu and H. Stahl, "Microbial utilization and biopolyester synthesis of bagasse hydrolysates," Bioresource Technology, vol. 99, no. 17, pp. 8042-8048, 2008.

[17] R. H. Marchessault, "Tender morsels for bacteria: recent developments in microbial polyesters," Trends in Polymer Science, vol. 4, no. 5, pp. 163-168, 1996.

[18] M. C. Sin, I. K. P. Tan, M. S. M. Annuar, and S. N. Gan, "Thermal behaviour and thermodegradation kinetics of poly(vinyl chloride) plasticized with polymeric and oligomeric mediumchain-length poly(3-hydroxyalkanoates)," Polymer Degradation and Stability, vol. 97, no. 11, pp. 2118-2127, 2012.

[19] I. K. P. Tan, K. Sudesh Kumar, M. Theanmalar, S. N. Gan, and B. Gordon III, "Saponified palm kernel oil and its major free fatty acids as carbon substrates for the production of polyhydroxyalkanoates in Pseudomonas putida PGA1," Applied Microbiology and Biotechnology, vol. 47, no. 3, pp. 207-211, 1997.

[20] M. C. Sin, I. K. P. Tan, M. S. M. Annuar, and S. N. Gan, "Kinetics of thermodegradation of palm kernel oil derived mediumchain-length polyhydroxyalkanoates," Journal of Applied Polymer Science, vol. 127, no. 6, pp. 4422-4425, 2012.

[21] S. Y. Hobbs and V. H. Watkins, "Morphology characterization by microscopy techniques," in Polymer Blends, D. R. Paul and C. B. Bucknall, Eds., John Wiley \& Sons, New York, NY, USA, 2000.

[22] D. J. Walsh, J. S. Higgins, and C. Zhikuan, "The compatibility of poly(methyl methacrylate) and chlorinated polyethylene," Polymer, vol. 23, no. 3, pp. 336-339, 1982.

[23] S. George, N. R. Neelakantan, K. T. Varughese, and S. Thomas, "Dynamic mechanical properties of isotactic polypropylene/ nitrile rubber blends: effects of blend ratio, reactive compatibilization, and dynamic vulcanization," Journal of Polymer Science, Part B: Polymer Physics, vol. 35, no. 14, pp. 2309-2327, 1997.

[24] K. T. Varughese, G. B. Nando, P. P. De, and S. K. De, "Miscible blends from rigid poly(vinyl chloride) and epoxidized natural rubber-part 1 Phase morphology," Journal of Materials Science, vol. 23, no. 11, pp. 3894-3902, 1988.

[25] K. P. Menard, Dynamic Mechanical Analysis: A Practical Introduction, CRC Press, New York, NY, USA, 1999.
[26] A. M. Stephan, T. P. Kumar, N. G. Renganathan, S. Pitchumani, R. Thirunakaran, and N. Muniyandi, "Ionic conductivity and FT-IR studies on plasticized PVC/PMMA blend polymer electrolytes," Journal of Power Sources, vol. 89, no. 1, pp. 80-87, 2000.

[27] S. Rajendran, M. Ramesh Prabhu, and M. Usha Rani, "Characterization of PVC/PEMA based polymer blend electrolytes," International Journal of Electrochemical Science, vol. 3, pp. 282290, 2008.

[28] A. Marcilla and M. Beltran, "Mechanisms of plasticizers action," in Handbook of Plasticizersin, G. Wypych, Ed., ChemTec Publishing, Toronto, Canada, 2004.

[29] O. Olabisi, L. M. Robeson, and M. T. Shaw, Polymer-Polymer Miscibility, Academic Press, New York, NY, USA, 1979.

[30] L. F. Sin, Polymeric Materials, Characterization of Materials Using Thermal Analysis Techniques, Edited by: S. Radhakrishna and A. K. Arof, Narosa Publishing House, New Delhi, India, 1998.

[31] S. Thomas and A. George, "Dynamic mechanical properties of thermoplastic elastomers from blends of polypropylene with copolymers of ethylene with vinyl acetate," European Polymer Journal, vol. 28, no. 11, pp. 1451-1458, 1992.

[32] L. E. Nielsen and R. F. Landel, Mechanical Properties of Polymers and Composites, Marcel Dekker, New York, NY, USA, 2nd edition, 1994.

[33] S. Radhakrishna and A. K. Arof, Polymeric Materials, Narosa Publishing House, New Delhi, India, 1998.

[34] T. J. Madera-Santana, M. Misra, L. T. Drzal, D. Robledo, and Y. Freile-Pelegrin, "Preparation and characterization of biodegradable agar/poly(butylene adipateco-terephatalate) composites," Polymer Engineering and Science, vol. 49, no. 6, pp. 11171126, 2009.

[35] R. Hernandez, J. J. Pena, L. Irusta, and A. Santamaria, "The effect of a miscible and an immiscible polymeric modifier on the mechanical and rheological properties of PVC," European Polymer Journal, vol. 36, no. 5, pp. 1011-1025, 2000.

[36] G. Wypych, Handbook of Plasticizers, ChemTech Publishing, Toronto, Canada, 2004. 

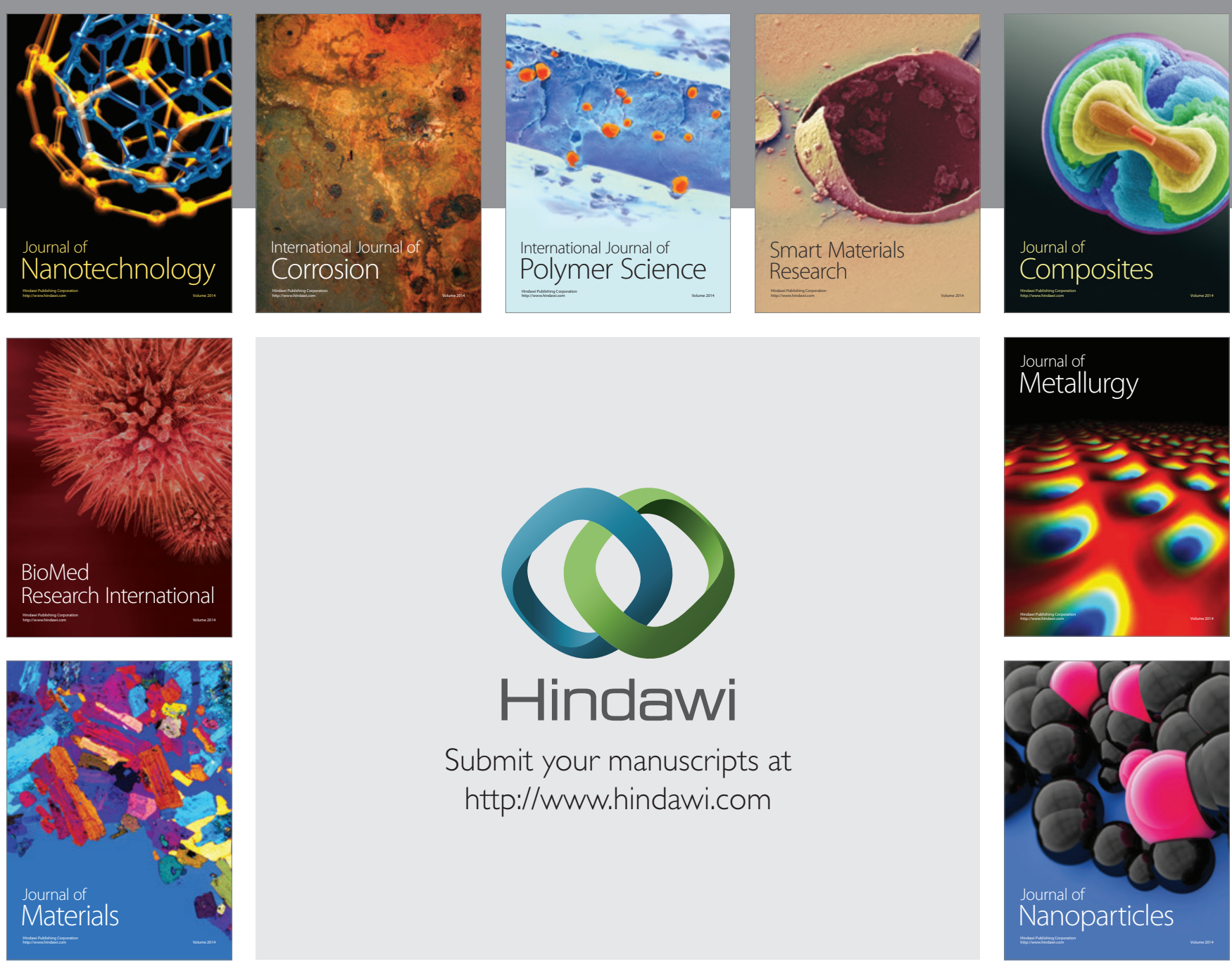

Submit your manuscripts at http://www.hindawi.com
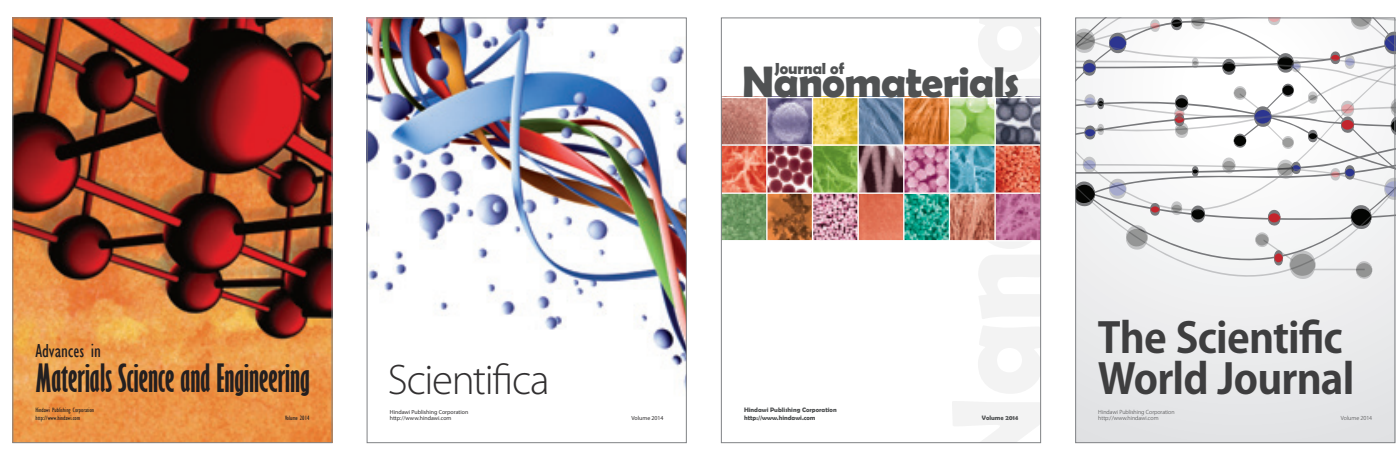

\section{The Scientific World Journal}
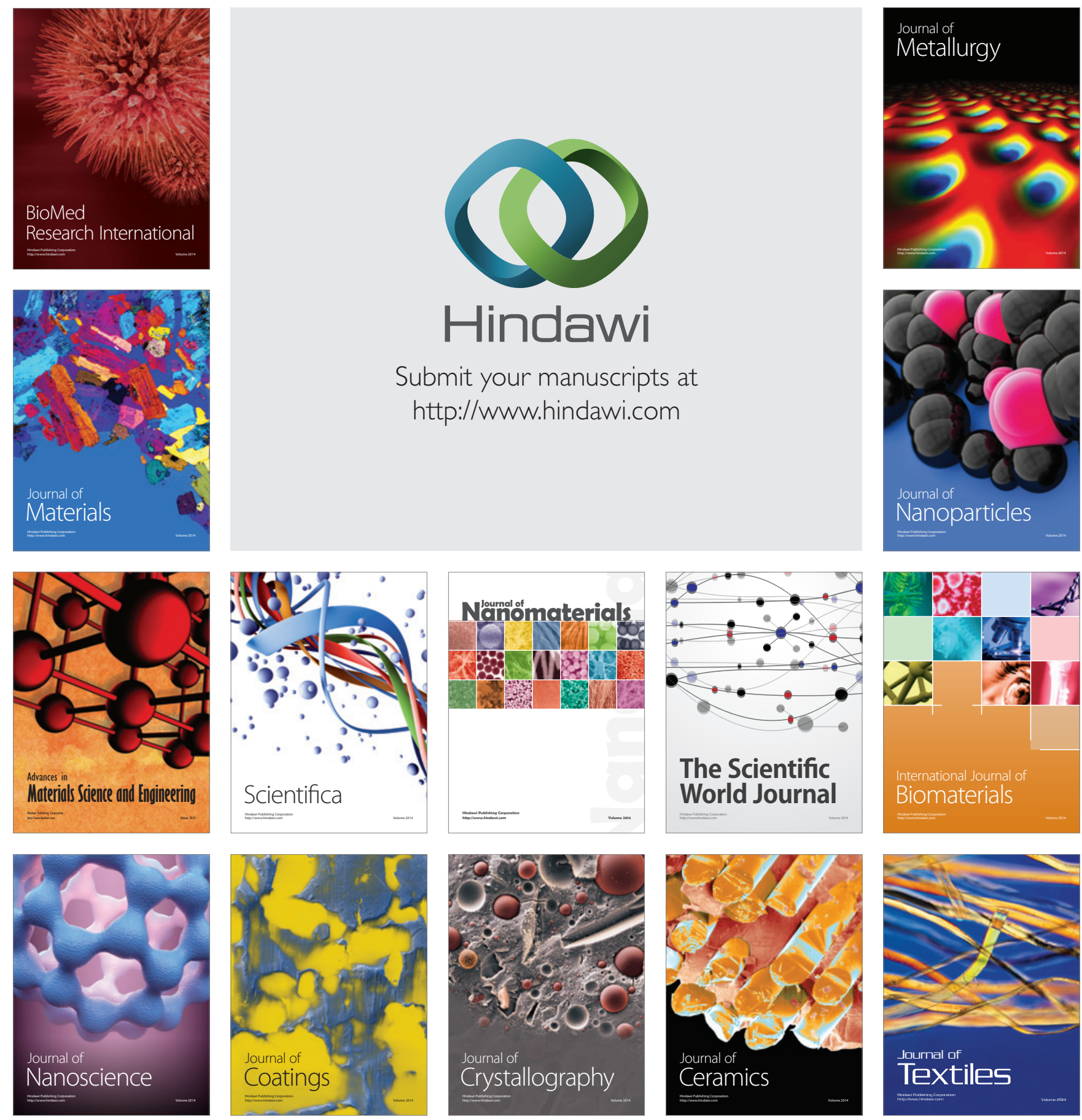